\title{
A Longitudinal Look at Habit Strength as a Measure of Success in Decreasing Prolonged Occupational Sitting: An Evidence-Based Public Health Initiative
}

\author{
Scott J. Pedersen ${ }^{*}$, P. Dean Cooley², Casey P. Mainsbridge1, Vaughan J. Cruickshank ${ }^{1}$ \\ ${ }^{1}$ Active Work Laboratory, College of Arts, Law, and Education, University of Tasmania, Launceston, Australia \\ ${ }^{2}$ Faculty of Education and Arts, Federation University, Ballarat, Australia \\ Email: *scott.pedersen@utas.edu.au
}

How to cite this paper: Pedersen, S.J., Cooley, P.D., Mainsbridge, C.P. and Cruickshank, V.J. (2018) A Longitudinal Look at Habit Strength as a Measure of Success in Decreasing Prolonged Occupational Sitting: An Evidence-Based Public Health Initiative Open Journal of Safety Science and Technology, 8, 35-48.

https://doi.org/10.4236/ojsst.2018.82004

Received: May 17, 2018

Accepted: June 24, 2018

Published: June 27, 2018

Copyright $(9) 2018$ by authors and Scientific Research Publishing Inc. This work is licensed under the Creative Commons Attribution International License (CC BY 4.0).

http://creativecommons.org/licenses/by/4.0/

\section{(c) (i) Open Access}

\begin{abstract}
Background: Sitting to perform desk-based work is considered to be a habit. To test this hypothesis, desk-based workers volunteered to be part of a yearlong pilot study utilising an e-health intervention designed to interrupt prolonged workplace sitting with movement breaks. Methods: Participants in a passive-prompt group had to engage with an e-health software programme on an hourly basis during work hours, while participants in an active-prompt group were allowed to postpone the prompt each hour. Daily adherence data and self-reported sitting habit strength were measured every 13 weeks for one year. A mixed design ANOVA was used to determine significant differences at the $\mathrm{p}<0.05$ level. Results: Passive-prompt participants reported significant improvements in reducing sitting habit strength over time, compared to active-prompt participants who actually reported increased sitting habit strength. Conclusions: This study provided preliminary evidence that changing desk-based workers' sitting habits might be more difficult than previously estimated and that passive-based interventions could be one solution.
\end{abstract}

\section{Keywords}

Workplace Health, Occupational Sitting, Habit Strength, E-Health Intervention

\section{Introduction}

The risks associated with sedentary behavior in the workplace are an ever-growing concern for employers. As most adults work full- or part-time, workplaces are 
integral sites for decreasing sedentary behaviors. Currently there is an emphasis in workplace health messages to decrease sitting time and increase incidental workday movement as a means of reducing sedentariness in the population. This emphasis is the result of a confluence of studies showing that prolonged bouts of sitting are a factor in the incidence of poor health outcomes [1], and that small periods of non-exercise physical activity (NEPA) offer health benefits [2] [3]. It has been suggested that sitting is a habit due to employees typically performing the majority of occupational tasks while desk-bound, in a repeated and consistent manner [4]. Interventions designed to reduce sitting time range from passive-based mechanisms such as standing desks to the less intrusive system of posters and signs. Nonetheless, both of these types of interventions are voluntary as workers can choose not to have a standing desk, choose not to elevate the desk, or simply ignore the poster prompts. Thus, these interventions suffer from similar adherence barriers as those experienced in voluntary exercise-based interventions. Recently, there have been a number of interventions that have adopted a more intrusive-based system whereby regardless of participant sedentary preferences, they are forced to engage in the intervention [5] [6] [7]. In the present pilot study we investigated the efficacy of a passive-based intervention over a 12-month period.

Reducing sitting time for desk-based employees is not akin to increasing voluntary exercise behavior. Sitting at work for desk-based employees is habit. Habits are learned behaviors that people automatically display in responses to specific environmental cues and reward [8] [9]. When this repetitive process is reinforced individuals develop a mental representation of an association between a goal and an action. Thus, when individuals are exposed to the environment stimulus they display the habitual behavior with little or no conscious thought [10] [11] [12] [13]. The benefit of this automatic process is efficiency [12]. We have argued elsewhere that sitting is a habit because it is routinely performed, reinforced, and occurs in the presence of environmental cues [3]. Thus, interventions based on theories of choice and attitude (i.e., Theory of Reasoned Action) are bound to reflect the same adherence issues because specific strategies are needed to break unwanted habits and create new wanted habits [14] [15]. One such strategy is the use of prompts (i.e., signs, music) within the decision-making environment to get the individual to reengage in conscious planning [16]. To change habits, the individual needs to re-engage in a decision making process about performing an alternative behavior to the behavior being executed.

Passive interventions are considered to remove almost all decision-making options (i.e., water fluoridation). They have higher compliance rates than those considered to be active, which have increased levels of individuality (i.e., seat-belt use in cars) [17] [18]. Recently we used a passive-based computer prompt intervention designed to decrease sitting time and increase NEPA in a workplace [5]. The passive prompt forced participants to regularly decide be- 
tween two alternatives; either, remain seated without a computer screen and spend considerable energy to find a work around, or simply take a movement break. Our results showed that over a short term (13-weeks), participants chose to significantly stand more and participate in more NEPA during work hours. Yet, despite the change in frequency of behavior, we were unable to claim that the habit of prolonged sitting had been replaced with the habit of more standing and moving. Thus decreasing the frequency of the unwanted behavior does not guarantee an increase in the wanted behavior. Moreover, it is unknown if unwanted and wanted behaviors can coexist.

Strength of habit, rather than using frequency measures, appears to be a more efficacious measure in determining the success of replacing unwanted behaviours with wanted behavior. Verplanken and Wood [19] showed that while repetition is needed for habits to develop, there are also personal factors that need to be taken into account before determining an occurrence of habit change. Thus, there is the possibility of false positives in the research findings. The suggestion [20] [21] to address the possible false positive findings is to use a measure of habit strength to better reflect changes in habit. Hence changes in strength of habit might better reflect the learning process of adoption of a new wanted habit. For example, Fujii and Kitamura [22] used free bus tickets to change the travel habits of automobile drivers to bus users. The introduction of free bus tickets resulted in a significant decrease in the habit strength of automobile use, but not a subsequent increase in the habit strength of bus use. Thus, while automobile drivers' attitude towards the unwanted habit changed while the free tickets were available, the authors noted that the strength of the wanted habit was not immediately observable. These findings imply that the development of new habits is time sensitive. That is, even if there is a decrease in the strength of the unwanted habit, it cannot be assumed that there is an automatically strengthening in the wanted behavior.

The use of frequency counts for standing and sitting occurrences might be a blunt axe when measuring changes in habit. It appears that replacing an unwanted habit with a wanted behavior is a complex undertaking that requires time and constant reminders, or prompts, about the alternative behaviors. For instance, attempts to replace elevator use with stair use in the workplace over a ten-week period did not increase stair use in 140 office-based employees [23]. Given the aforementioned issues associated with measuring habit change we investigated this variable through a strength measure rather than a frequency measure [20] [21]. We decided to manipulate the type of prompting system within a yearlong workplace e-health software intervention designed to decrease the unwanted behavior of prolonged occupational sitting time (POST) in a cohort of desk-based workers to test its efficacy over 12 months. In particular we hypothesized that desk-based workers who were exposed to a regular passive prompt to engage in the wanted behavior of regular movement breaks throughout the workday, would experience a significant decrease in the strength of the 
unwanted behavior of unbroken sitting compared to desk-based workers who were able to choose when to engage in the wanted behavior of movement breaks.

\section{Method}

\subsection{Participants}

Desk-based employees from the Tasmania State Fire Department (TSFD) were asked to participate in a trial for a new workplace e-health programme at their centralized, urban administration worksite. Considering the pilot nature of this feasibility study to see if a workplace e-health programme could be adhered to and successful in altering sitting habits over the course of a year, no a priori sample size was calculated. We simply asked the agency for as many desk-based participants as possible. The participants $(\mathrm{N}=14)$ in this sample (female $=4$, Mage $=42.25 \pm 10.05$ years; male $=10$, Mage $=48.20 \pm 12.68$ years ) volunteered for a field-based, longitudinal trial over one year. They were pre-screened to ensure they had desk-based job responsibilities, daily use of a desktop computer, were free from pre-existing health conditions [24], and were ready to engage in behavior change [25]. Participants worked an average of 35.51 \pm 10.24 hours per week. All participants provided informed consent and the study was approved by the Tasmanian Social Science Human Research Ethics Committee (Approval \#: H0018075).

\subsection{Materials}

\subsubsection{Sitting Habit Strength}

The dependent variable in this study was measured with a modified version of Verplanken and Orbell's [20] self-report habit index. Originally intended to measure the habit of smoking, we modified this inventory to address the behavior of sitting while at work. This inventory has been previously modified [26] to measure the habit strength of sedentary behavior. More specifically, Maher and Conroy examined the moderating influence of daily action planning on physical activity and sedentary behavior habit strength. We first piloted the 12-item survey on a panel of six health and education university-level research experts to query the transferability of our major modification (removing the term "smoking" and replacing it with "sitting"). Four of these experts recommended removing the fourth item, "Not sitting makes me feel weird if I do not do it" because of the ambiguity of the statement. Thus, we settled on an 11-item inventory using a seven point Likert scale ( $1=$ Strongly disagree to $7=$ Strongly agree $)$ to measure the habit strength of sitting in the workplace. Since all of these items had a positive direction for response we chose to sum the items for a total score of strength of habitual sitting. This sum score served as the dependent variable for our investigation. The survey took less than 10 minutes to complete. Reliability of this modified survey was measured and reported in the results section.

\subsubsection{E-Health Software}

The e-health software, Exertime, was designed by the researchers to prompt em- 
ployees to periodically break long periods of sitting by standing up to engage in a brief movement break during their work hours [5]. The software contains an internal timed prompt that signifies to computer users that the programme is about to initiate (Figure 1). Once the software initiates, a cover screen then occupies the entire computer screen(s). Employees are thus compelled to engage with the programme before being able to return to their computer work. This prompt automatically initiated every 45 minutes of the workday. The 45 -minute prompting time was proposed by the TSFD occupational health and safety manager who based this decision on recommendations in the guidance note for the prevention of occupational overuse syndrome in keyboard employment [27], which specifies that all computer-based employees should remove themselves from a sedentary position for a short period every 60 minutes throughout the workday.

The initiation of the Exertime sequence begins with a cover screen containing a variety of thumbnail icons of examples of office-appropriate, movement break options such as one-legged squats, desk push-ups, or climbing the office stairs (Figure 2). After choosing a movement break, a timer begins while a video plays the movements of a human model performing the chosen movement break in an office environment. Once employees selected an activity it was up to them to decide how to engage with the prompted suggestion. There was no set requirement placed on employees in terms of repetitions or exercise intensity. Upon completing each movement break participants were prompted to self-report the number of repetitions they performed within the software. This progress was then graphically presented to employees indicating the amount of time they had spent performing movement breaks, and the amount of calories they expended during the workday. Research has shown that feedback and regular monitoring reinforces health behavior change [28]. These forms of self-reported data were not of interest to the researchers. Once employees' data were recorded, the Exertime sequence terminated and they were able to regain control over their computer screens to continue with their work responsibilities.

For this study, we used two prompt conditions (passive and active) to compare mean scores for habit strength for sitting at work across five test periods

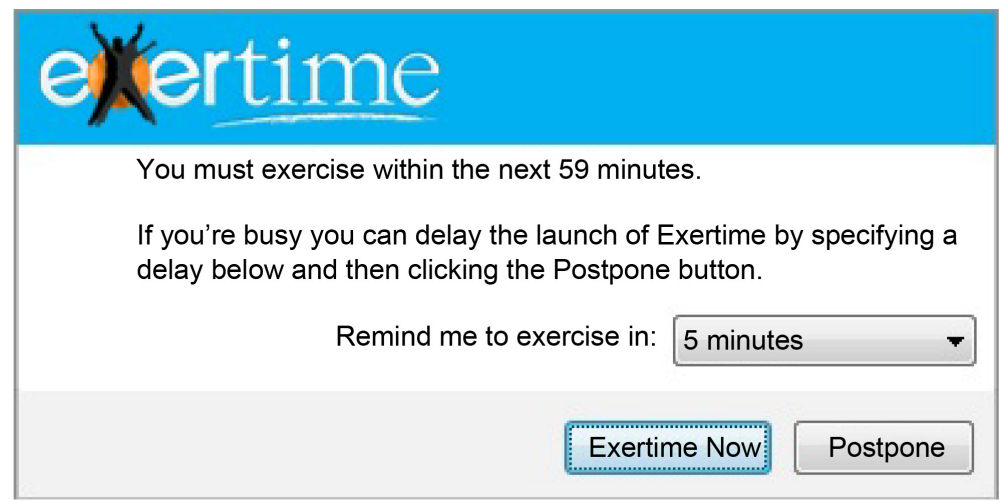

Figure 1. Exertime internal timed prompt screen. 


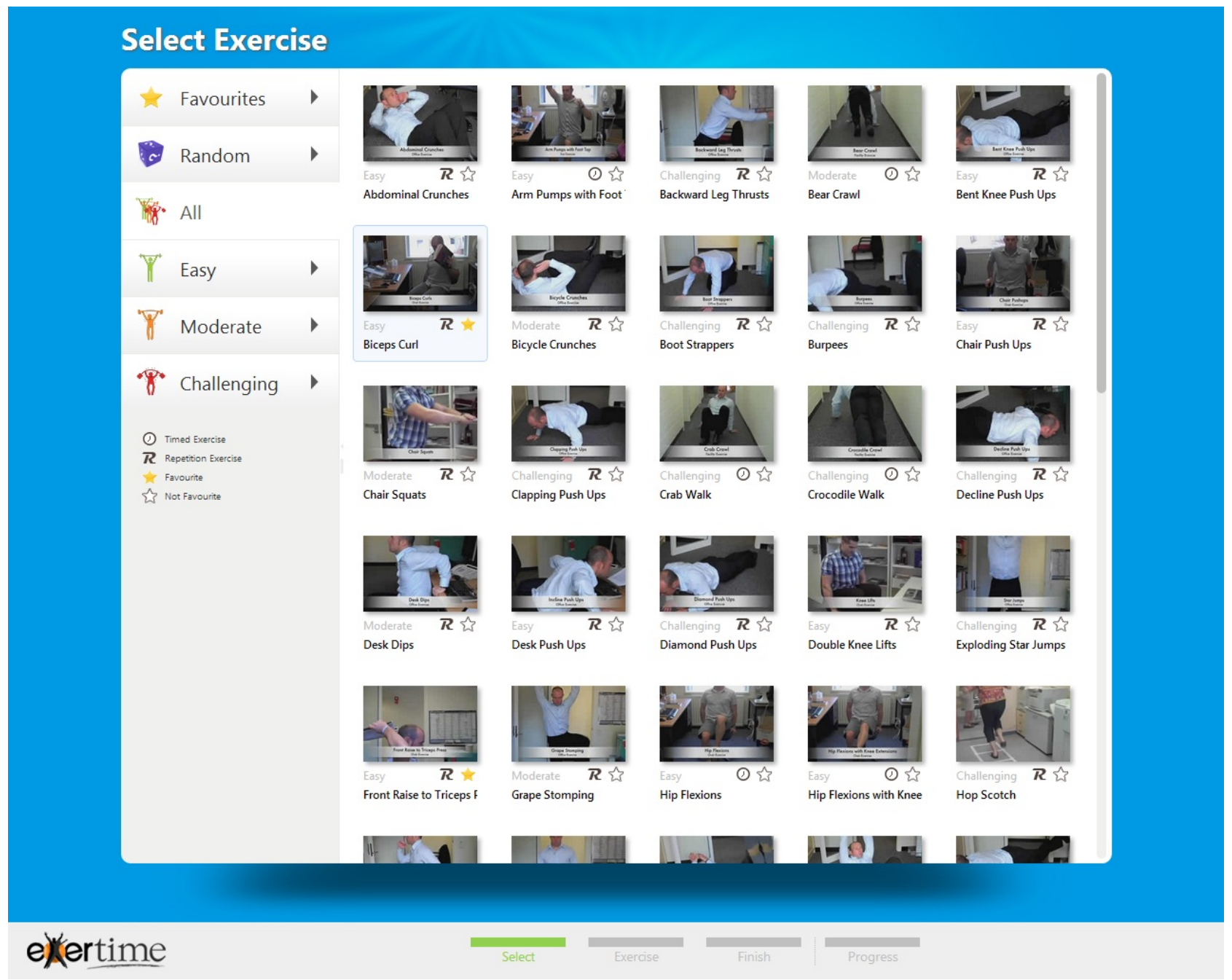

Figure 2. Exertime exercise selection screen.

(baseline, post-tests every 13 weeks for one year). The assessment of desk-based employees taking their own initiative to engage with the e-health programmme was the reason for the design selection of the programme. In the passive condition, participants could only postpone the initiation of the software for a maximum of 15 minutes after each 45-minute prompt. After a maximum of $15 \mathrm{mi}$ nutes, the software automatically initiated and participants had to complete the Exertime sequence before regaining control of their work computer. In the active condition, the software functioned just as the passive condition, except participants were able to indefinitely postpone the engagement of the Exertime sequence. Thus, participants in the active condition could postpone the software as much as they liked during work.

\subsection{Procedures}

All TSFD employees interested in participating in the workplace e-health programme attended an educational session with the research team at the TSFD training center $(\mathrm{N}=25)$. During this session participants were provided a 60 
min presentation on the negative health effects associated with POST (10 min), general instructions for performing appropriate workplace movement breaks (20 $\mathrm{min})$, and a demonstration and user-trial of the e-health software (30 $\mathrm{min})$. During this session participants were told how the e-health software could operate on their work computers, in both passive and active prompt formats. At the conclusion of the education session, all attending TSFD staff were informed about the present study and ask to decide if they would consent to participate. All staff received a study package, which contained the study purpose, requirements of participation, and consent form. All consent forms were return via internal mail, with 56 per cent consenting and the remaining choosing not to participate in the study. Although not a requirement, some who chose not to participate did indicate a range of reasons for their decisions on the returned consent forms. These reasons included; the length of the study $(n=4)$, impeding long service leave $(n=3)$, and personal leave $(n=2)$. Before a second meeting with consenting participants, the TSFD requested a meeting about the conditions of the study. In particular, the TSFD requested that participants in the study be allowed to self-select into a preferred treatment condition. The TSFD request regarding self-selection into groups was based on concerns that under some work circumstances such as emergencies the passive prompt was a potential risk to work flow, particularly for managers and supervisors.

Of course, this procedure raised concerns of sample bias. There is precedence for such bias with evidence that self-selection has little or no impact prevalence estimates [29] [30]. Thus, we decided that we had to acquiesce, and allow participants the opportunity to self-select prompt group based on their perceptions of a need to have control over work flow.

Despite the researchers' concern over self-selection, at a second participant meeting, only three (Mage $=44.00 \pm 19.00$ years) chose the active prompt condition, whereas eleven participants chose to be in the passive prompt condition (Mage $=47.18 \pm 10.51$ years). As researchers, we were aware of which condition had resulted in compliance in previous studies [3] [5] [6]; nonetheless, we were asked questions about the effectiveness of each condition. The researchers were all present and ensured that questions were answered neutrally as possible to further avoid contaminating the sample. Participants were reminded that their involvement in the yearlong study was strictly voluntary and they could withdraw at any time. The software was then installed on all computers for one year. Those who had chosen not to be in the study also had the software installed on their computers. The only prompts the participants would receive during this time were from their computer, not the research team. The participants in the study upon engaging the software for the first time, were re-directed to a short online survey, which contained the strength of sitting habit measure. Thereafter, participants completed the same survey every 13 -weeks. The software automatically logged the frequency of daily usage of the e-health programme. Adherence rates are reported in the results. 


\subsection{Data Analysis}

Cronbach's alpha coefficient was calculated to report the reliability of the 11-item survey. A 2 (Prompt: Passive/Active) $\times 5$ (Test: Pre-test/Post-test 1/Post-test 2/Post-test 3/Post-test 4) mixed design ANOVA was used to determine significant differences on the dependent variable (sitting habit strength), using a critical alpha level of 0.05 . Cohen's d statistic was used to calculate the effect size of any significant findings. No a priori power analyses were conducted because of the absence of relevant intervention research. All data were analyzed using IBM SPSS version 22.0.

\section{Results}

We were faced with a dilemma that was unfolding as our study progressed through the year. The number of participants in the study had fallen to very small numbers at the end of the study due to two events. The first wave of withdrawal started in an unusually early, but highly active bushfire season in Tasmania. Starting at the 15th week of the study we experienced participants $(n=4)$ who withdrew because of a change to their work status to a more critical role during the firefighting coordination. These withdrawals were essential for public health and safety. Then from six months onwards, we experienced a perplexing withdrawal of participants $(n=3)$ who held managerial positions. All of these withdrawals were exercise and health conscious individuals, who were the instigators of the intervention, acted as organization/office role models, understood the health effects of prolonged sitting, and were active in promoting the benefits of regular NEPA across the TSFD. Moreover, their job roles had not changed nor their health statuses. We intend to pursue this phenomenon. It is possible that the TSFD employee occupations and inherent roles and responsibilities associated with these are atypical to that of desk-based employees. Furthermore, a field-based yearlong study with low participant numbers could have impacted upon the reasons for withdrawal. The dropout data is reported in Table 1, along with descriptive daily e-health software usage data for the two groups.

Faced with low numbers, we decided to include additional information [31]. As our original intent was to test the efficacy of an e-health programme and not

Table 1. Daily use of the e-health software by group across time.

\begin{tabular}{clllc}
\hline & \multicolumn{1}{c}{ Passive } & \multicolumn{2}{c}{ Active } \\
\cline { 2 - 4 } & Mean $(S D)$ & $n$ & Mean $(S D)$ & $n$ \\
\hline Post-test 1 & $8.59(5.09)$ & 11 & $6.64(1.00)$ & 3 \\
Post-test 2 & $7.79(3.05)$ & 7 & $6.85(1.11)$ & 3 \\
Post-test 3 & $6.74(0.93)$ & 6 & $5.49(0.65)$ & 3 \\
Post-test 4 & $7.03(0.51)$ & 4 & $5.36(0.83)$ & 3 \\
\hline
\end{tabular}

Table 1 Daily Use of the e-health Software by Group across Time. Values represent means (SD) of daily use per day for the previous 13 weeks of treatment; $n$ represents the number of group participants still involved in the study. 
the effectiveness, we included standard error of the mean measurements in the reported descriptive statistics, and effect size to further interpret any significant findings.

Cronbach's alpha $(\alpha=0.90)$ indicated that the self-report of habitual sitting, across the two groups, was a reliable and internally consistent measure. There was a significant interaction between prompt and test, $\mathrm{F}(4,32)=2.94, \mathrm{p}=0.04$, while neither main effect was significant. Follow-up simple main effects analysis revealed that only the passive prompt group had a significant change in the habit strength dependent variable over time, $F(4,32)=3.06, p=0.03$. Tukey's post-hoc test of this simple main effect indicated that the passive prompt group significantly reduced their self-reported sitting habits at work from pre-test $(M=58.09 \pm$ $3.81, \mathrm{n}=11)$ to post-test $4(\mathrm{M}=46.00 \pm 10.21, \mathrm{n}=4)$ with a large effect size $(\mathrm{d}=$ $0.71)$.

Over the course of the study there were non-significant differences between the passive and active prompt conditions for use of the e-health software (Table 1). Evident in the results is that there was a decrease in usage over time for both groups.

As can be seen in Figure 3 while the passive prompt group exhibited a progressive decrease in self-reported sitting habits over the yearlong study, the active prompt group $(\mathrm{n}=3)$ displayed an initial, non-significant decrease in this self-report over the first 13 weeks between pre-test $(\mathrm{M}=54.33 \pm 10.59)$ and post-test $1(\mathrm{M}=47.00 \pm 9.50)$, but then steadily increased their sitting habit

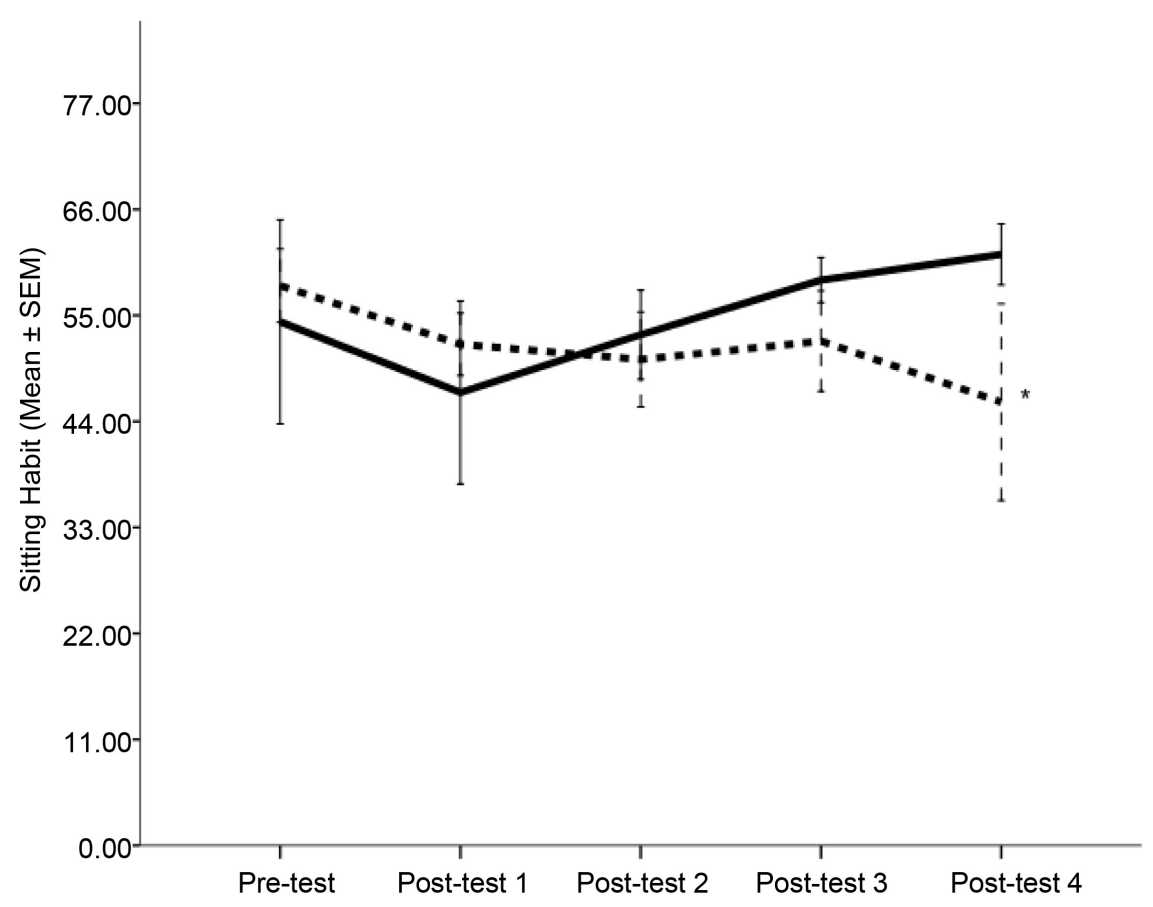

Figure 3. Sitting habit strength by group over time. Broken line represents the passive prompt group. Solid line represents the active prompt group. Error bars represent \pm 1 standard error of the mean. ${ }^{\star}$ Signifies that this mean value is significantly less than the group's pre-test mean value. 
strength over the remainder of the study. In fact, their post-test 4 measure $(\mathrm{M}=$ $61.33 \pm 3.18$ ) was the strongest sitting habit strength recording for the duration of the study, by either group.

\section{Discussion}

The findings of our small-scale, yearlong, field-based pilot research study provide preliminary evidence to support our hypothesis that a passive-based prompt is more effective in decreasing the strength of the unwanted behavior of unbroken sitting. Congruent with other research [5] [6] [18] [32], passive-based prompting interventions seem to be more successful in reducing the strength of unwanted behavior. Based on our results, it would appear that the habit of sitting at work is robust as the strength of the behavior did not decrease to negligible levels, even after educating the participants about the negative health effects associated with prolonged sitting. Those participants in the active prompt condition also reported a similar initial decrease in the strength of the sitting habit over the first three months of the study. This decline could be explained by the educational sessions and associated health warnings. But, similar to voluntary-based exercise interventions, after 13 weeks, the strength of the unwanted habit returned to pre-intervention level while those in the passive prompt condition showed a continual decrease in the strength of the unwanted behavior. This result gives some additional insight to the complexity of changing health behaviors and adherence. For voluntary exercise interventions, perhaps a more stringent adherence mechanism might result in less withdrawal in the initial phases of changing behavior and hence decrease the unwanted behavior strength. Also these results might give researchers pause for thought in using frequency of behavior as a measure of intervention success.

First, to the best of our knowledge this is the first report of the efficacy of a regular passive prompt designed to decrease habit strength for the unwanted behavior of unbroken sitting. Our study provides preliminary evidence that habit strength does change over time in response to reduced decision-making. Nonetheless, to change the strength of the habit, more passive measures might be needed to ensure the compliance of desk-based employees to stand and move more, and sit less at work. Previous approaches (e.g., [5]) have treated sitting at work as a voluntary behavior and hence used similar approaches as those used for voluntary exercise behavior. In short, we argue that these interventions have limited sustainability because without the conscious reminder to engage in the new behavior, habit strength for sitting is resilient. Second, changing health behavior at work is vexed with problems of sustainability. Our preliminary results give an indication that despite a year of engagement in the new behavior, the desire to perform the old behavior is still present. From a health behavior change perspective, these preliminary results might give researchers pause for thought about the sustainability of other workplace health and wellbeing programmes. This is informative for the long-term effect of education only-based workplace 
health and wellbeing programmes. Participants in our study who only received education plus the self-initiated software reported non-significant changes in sitting habit strength. Moreover as depicted in Table 1, they engaged in less movement breaks during work periods. Finally, despite small numbers, this is the first report addressing movement breaks in POST through a longitudinal study. The use of future longitudinal field studies might allow the presentation of a more cogent picture of the effectiveness of interventions in terms of sustainability and health outcomes. We advocate for this study to be replicated across a larger sample, perhaps in more controlled settings, so that more generalizable findings can be produced.

We recognize there are limitations to our study. First, the study was a field trial in an emergency department. A number of factors converged to reduce the transferability of the results. The nature of emergency work and an emergency within the community (e.g., summer fires), changed the objectives of the study. Thus, the final numbers were small. This is problematic in drawing any firm conclusions. The relatively small sample size limits the impact of the study as well as the limitation of only one organization being involved. Future studies should consider enlisting multiple organizations to increase sample size and enable an investigation of the effect workplace support has on behavior change. Second, the self-report method of data collection should be viewed with caution due to the identified limitations of self-report methods [33]. Nonetheless, we found the likelihood of employees willingly becoming participants was increased when using such an unobtrusive method [34]. Moreover, this was the first study, to our knowledge, that adapted a habit strength survey to address POST. Thus, there is no criterion scale to follow in terms of what scores indicate a strong versus a weak habit for strength of POST. More research using this tool is warranted so that comparable data can used to make more meaningful interpretations out of using this type of self-report to measure POST habit strength. Finally, we did not measure changes in the habit strength of incorporating movement breaks into work time because our primary aim for this paper was to break the habit of POST. Future investigations should consider both of these variables to ascertain success of workplace health and wellbeing programmes designed to change associated health habits.

\section{Conclusion}

Changing a lifetime habit, such as sitting and in particular changing the habit for only one environment (i.e., the workplace), took almost a year of continuous passive prompting e-health intervention to engage in an alternative behavior. This observation should give researchers further impetus to engage in future studies of the length of time needed to extinguish unwanted health habits. Moreover, health researchers and policy makers perhaps should reconsider more passive-based health interventions to explore habit change. Changing the habit of POST appears to result in positive health changes and as such, interventions 
need to be developed and implemented. The use of a habit index appears to offer an alternative and a complementary approach to report on the effectiveness of health behavior change interventions.

\section{Acknowledgements}

The study was funded by the Tasmanian Government Healthy@Work grant scheme.

\section{References}

[1] Dunstan, D.W., Thorp, A.A. and Healy, G. (2011) Prolonged Sitting: Is It a Distinct Coronary Heart Disease Risk Factor. Current Opinion in Cardiology, 26, 412-419. https://doi.org/10.1097/HCO.0b013e3283496605

[2] Dunstan, D.W., Howard, B., Healy, G. and Owen, N. (2012) Too Much Sitting-A Health Hazard. Diabetes Research and Clinical Practice, 97, 368-376. https://doi.org/10.1016/j.diabres.2012.05.020

[3] Mainsbridge, C.P., Cooley, P.D., Fraser, S.P. and Pedersen, S.J. (2014) The Effect of an E-Health Intervention Designed to Reduce Prolonged Occupational Sitting on Mean Arterial Pressure. Journal of Occupational and Environmental Medicine, 56, 1189-1194. https://doi.org/10.1097/JOM.0000000000000243

[4] Owen, N., Bauman, A. and Brown, W. (2009) Too Much Sitting: A Novel and Important Predictor of Chronic Disease Risk. British Journal of Sports Medicine, 43, 81-83. https://doi.org/10.1136/bjsm.2008.055269

[5] Cooley, P.D. and Pedersen, S.J. (2013) A Pilot Study of Increasing Nonpurposeful Movement Breaks at Work as a Means of Reducing Prolonged Sitting. Journal of Environmental and Public Health, 2013, Article ID: 128376. https://doi.org/10.1155/2013/128376

[6] Pedersen, S.J., Mainsbridge, C. and Cooley, P.D. (2014) An E-Health Intervention Designed to Increase Workday Energy Expenditure by Reducing Prolonged Occupational Sitting Habits. Work, 49, 289-295.

[7] Evans, R.E., Fawole, H.O., Sheriff, S.A., Dall, P.M., Grant, P.M. and Ryan, C.G. (2012) Point-of-Choice Prompts to Reduce Sitting Time at Work: A Randomized Trial. American Journal of Preventive Medicine, 43, 293-297. https://doi.org/10.1016/j.amepre.2012.05.010

[8] Hull, C.L. (1943) Principles of Behavior: An Introduction to Behavior Theory. Appleton-Century, Oxford, England.

[9] Tolman, E.C. (1938) The Determiners of Behavior at a Choice Point. Psychological Review, 45, 1-41. https://doi.org/10.1037/h0062733

[10] Aarts, H. and Dijksterhuis, A. (2000) Habits as Knowledge Structures: Automaticity in Goal-Directed Behavior. Journal of Personality and Social Psychology, 78, 53-63. https://doi.org/10.1037/0022-3514.78.1.53

[11] Bargh, J.A. and Gollwitzer, P.M. (1994) Environmental Control of Goal-Directed Action: Automatic and Strategic Contingencies between Situations and Behavior. In: Spaulding, W.D., Ed., Integrative Views of Motivation, Cognition, and Emotion. Nebraska Symposium on Motivation, University of Nebraska Press, Lincoln, NE, US, 3-51.

[12] Verplanken, B. and Aarts, H. (1999) Habit, Attitude, and Planned Behavior: Is Habit an Empty Construct or an Interesting Case of Goal-Directed Automaticity? Eu- 
ropean Review of Social Psychology, 10, 101-134. https://doi.org/10.1080/14792779943000035

[13] Holland, R.W., Aarts, H. and Langendam, D. (2006) Breaking and Creating Habits on the Working Floor: A Field-Experiment on the Power of Implementation Intentions. Journal of Experimental Social Psychology, 42, 776-783. https://doi.org/10.1016/j.jesp.2005.11.006

[14] Verplanken, B., Aarts, H., van Knippenberg, A. and Moonen, A. (1998) Habit Versus Planned Behavior: A Field Experiment. British Journal of Social Psychology, 37, 111-128. https://doi.org/10.1111/j.2044-8309.1998.tb01160.x

[15] Fry, J.P. and Neff, R.A. (2009) Periodic Prompts and Reminders in Health Promotion and Health Behavior Interventions: Systematic Review. Journal of Medical Internet Research, 11, e16. https://doi.org/10.2196/jmir.1138

[16] Webb, T.L. and Sheeran, P. (2006) Does Changing Behavioral Intentions Engender Behavior Change? An Analysis of the Experimental Evidence. Psychological Bulletin, 132, 249-268. https://doi.org/10.1037/0033-2909.132.2.249

[17] Real, K. (2008) Information Seeking and Workplace Safety: A Field Application of the Risk Perception Attitude Framework. Journal of Applied Communication Research, 36, 338-358. https://doi.org/10.1080/00909880802101763

[18] Williams, A.F., Wells, J.K., McCartt, A.T. and Preusser, D.F. (2000) Buckle Up Now! An Enforcement Program to Achieve High Belt Use. Journal of Safety Research, 31, 195-201. https://doi.org/10.1016/S0022-4375(00)00036-0

[19] Verplanken, B. and Wood, W. (2006) Interventions to Break and Create Consumer Habits. Journal of Public Policy \& Marketing, 25, 90-103.

https://doi.org/10.1509/jppm.25.1.90

[20] Verplanken, B. and Orbell, S. (2006) Reflections of Past Behavior: A Self-Report of Habit Strength. Journal of Applied Social Psychology, 33, 1313-1330.

https://doi.org/10.1111/j.1559-1816.2003.tb01951.x

[21] Verplanken, B. (2006) Beyond Frequency: Habit as Mental Construct. British Journal of Social Psychology, 45, 639-665. https://doi.org/10.1348/014466605X49122

[22] Fujii, S. and Kitamura, R. (2003) What Does a One Month Free Bus Ticket Do to Habitual Drivers? An Experimental Analysis of Habit and Attitude Change. Transportation, 30, 81-95. https://doi.org/10.1023/A:1021234607980

[23] Avitsland, A., Solbraa, A.K. and Riiser, A. (2017) Promoting Workplace Stair Climbing: Sometimes, Not Interfering Is the Best. Archives of Public Health, 75, 2. https://doi.org/10.1186/s13690-016-0170-8

[24] British Columbia Ministry of Health (1978) PARQ Validation Report.

[25] Marcus, B.H., Rossi, S.V.C., Niarua, R.S. and Rossi, J.S. (1992) Self-Efficacy and the Stages of Exercise Behavior Change. Research Quarterly Exercise Sport, 63, 60-66. https://doi.org/10.1080/02701367.1992.10607557

[26] Maher, J.P. and Conroy, D.E. (2015) Habit Strength Moderates the Effects of Daily Action Planning Prompts on Physical Activity but not Sedentary Behavior. Journal of Sport \& Exercise Psychology, 37, 97-107. https://doi.org/10.1123/jsep.2014-0258

[27] Worksafe Australia (1996) Guidance Note for the Prevention of Occupational Overuse Syndrome in Keyboard Employment. National Occupational Health and Safety Commission. National Government Publishing Service.

[28] Michie, S., Ashford, S., Sniehotta, F.F., Dombrowski, S.U., Bishop, A. and French, D.P. (2011) A Refined Taxonomy of Behavior Change Techniques to Help People Change Their Physical Activity and Healthy Eating Behaviors: The CALORE Tax- 
onomy. Psychology \& Health, 26, 1479-1498.

https://doi.org/10.1080/08870446.2010.540664

[29] Nilsen, R.M., Vollset, S., Gjessing, H., Skjaereven, R., Melve, K., Schreuder, P., Alsaker, E.R., Haug, K., Daltveit, A.K. and Magnus, P. (2009) Self-Selection and Bias in a Large Prospective Pregnancy Cohort in Norway. Paediatric and Perinatal Epidemiology, 23, 597-608. https://doi.org/10.1111/j.1365-3016.2009.01062.x

[30] Sogarrd, A.J., Selmer, R., Bjertness, E. and Thelle, D. (2004) The Oslo Health Study: The Impact of Self-Selection in a Large, Population-Based Survey. International Journal for Equity in Health, 3, 3. https://doi.org/10.1186/1475-9276-3-3

[31] Evans, C.H. and Ildstad, S.T. (2001) Small Clinical Trials: Issues and Challenges. National Academy Press, Washington DC.

[32] Williams, A.F. (1982) Passive and Active Measures for Controlling Disease and Injury: The Role of Health Psychologists. Health Psychology, 1, 399-409. https://doi.org/10.1037/h0090242

[33] Brener, N.D., Billy, J.O.G. and Grady, W.R. (2003) Assessment of Factors Affecting the Validity of Self Reported Health-Risk Behavior among Adolescents: Evidence From the Scientific Literature. Journal of Adolescent Health, 33, 436-457. https://doi.org/10.1016/S1054-139X(03)00052-1

[34] Rothengatter, T. (1982) The Effects of Police Surveillance and Law Enforcement on Driver Behavior. Current Psychology: Research and Reviews, 2, 349-358.

https://doi.org/10.1007/BF02684467 